\title{
Background Gamma Radiation Mapping in Bangladesh: Radioactivity in the Surface Soil of 'BhawalGahr' Area of Gazipur
}

\author{
S. S. Islam ${ }^{1 *}$, M. A. Haydar ${ }^{2}$, M. I. Ali ${ }^{2}$, D. Paul ${ }^{2}$, M. L. Ali ${ }^{2}$ andS. M. A. Islam ${ }^{1}$ \\ ${ }^{I}$ Dept. of Physics, Jahangirnagar University, Savar, Dhaka \\ ${ }^{2}$ Health Physics and Radioactive Waste Management Unit (HPRWMU), Institute of Nuclear Science and \\ Technology,Atomic Energy Research Establishment,Bangladesh Atomic Energy Commission (BAEC) Savar, \\ Dhaka, Bangladesh.
}

\begin{abstract}
The total background radiation in the earth's environment is due to the contributions from natural (cosmic and terrestrial) as well as artificial (fall-out from nuclear weapon test, nuclear accidents, discharge from nuclear reactors etc.) radiation sources. It comes mainly from uranium ${ }^{238} U$ series, thorium ${ }^{232} \mathrm{Th}$ series and radioisotope of potassium, ${ }^{40} \mathrm{~K}$. Moreover, fission products such as ${ }^{134} \mathrm{Cs},{ }^{137} \mathrm{Cs},{ }^{90} \mathrm{Sr}$ etc. may spread as fallout radiation in the environment. Natural environmental radioactivity depends on the geological and geographic conditions, and appears at different levels in the soils of each different geological region. Therefore, it is worthy of investigating background radioactivity originating from natural and probable artificial radioactive sources. Country-wide background gamma radiation mapping program has been initiated in Bangladeshby dividing the whole country primarily into $\sim 5 \mathrm{~km} \times \sim 5 \mathrm{~km}\left(1^{\prime} \times 1^{\prime}\right.$ in GPS scale) systematic square grids. About $30 \mathrm{~km} \times 30 \mathrm{~km}$ area of forest land of Gazipur district called the 'BhawalGahr' (including the Bhawal National Park) bordering Mymensinghand Tangail districts was selected for sampling for this study. Soil samples at $0-5 \mathrm{~cm}$ depth were collected from the grid-node points of the squaregrids. Gamma ray spectrometry technique using a High Purity Germanium (HPGe) detector of $20 \%$ relative efficiency was used to detect the probable radionuclides and calculate of their activity concentrations in the samples. The activity concentrations of ${ }^{226} \mathrm{Ra},{ }^{232} \mathrm{Th}$ and ${ }^{40} \mathrm{~K}$ in these soil samples varied from $49.92 \pm 8.83$ to $83.44 \pm 6.09 \mathrm{~Bq} / \mathrm{kg}, 76.83$ \pm 5.44 to $126.45 \pm 8.33 \mathrm{~Bq} / \mathrm{kg}$ and $363.71 \pm 92.33$ to $585.91 \pm 106.12 \mathrm{~Bq} / \mathrm{kg}$, respectively. As Bangladesh is actively considering embarking upon nuclear power programto improve its energy mix and neighbouring countrieshave a number of nuclear power plants in operation, therefore, this background radioactivity database would be useful as a baseline data in time of any nuclear incidentin this region.
\end{abstract}

Key Words: Radionuclide; Activity Concentration; HPGe detector, Radiological Health Hazard

\section{Introduction}

Radiation is everywhere, including in the soil. Radionuclides become a part of the soil in three ways: (i) as part of Earth's original crust (primordial radionuclides) (ii) produced and deposited by cosmic ray interactions (cosmogenic radionuclides) and (iii) through man-made releases (man-made radionuclides and activities)[1]. Primordial radionuclides such as uranium-235, uranium-238, thorium-232, and potassium-40 are left over from the creation of the earth with typical have half-lives of hundreds of millions of years. Primordial radionuclides end up in soil as part of the rock cycle, which includes weathering. Cosmogenic radionuclides such as carbon-14, tritium-3, and beryllium-7 are continuously produced by bombardment of stable nuclides by cosmic rays, primarily in the atmosphere and can have long half-lives, but the majority has shorter half-lives than the primordial radionuclides. Some of these radionuclides fall to earth and are deposited on the soil. The third way radionuclides enter the soil is through man-made activities, such as the fallout from atmospheric testing of nuclear weapons and radiological events like accidents and leakages from nuclear facilities. The radioactive particles from these events travel around the world on streams of air and due to the weight of the particles and weather (e.g., heavy rain) soonthose particles end up to the ground. Natural radioactivity in soil varies on soil type, mineral make up and density. Radionuclides in the soil can move into the water, air and even our food supply.

Natural radiations in the environment, nuclear tests, accidents and possible leakages from nuclear facilitiesmayresult in serious problems for environment and human health. Naturalenvironmental radioactivity arises mainly from primordial radionuclides from the ${ }^{235} \mathrm{U},{ }^{238}$ Uand ${ }^{232} \mathrm{Th}$ series,followed by ${ }^{40} \mathrm{k}$. Gamma radiation emitted from those naturally occurring radionuclides and from radionuclides deposited on the ground are the main external sources of radiation exposure of the human body. Natural environmental radioactivity and associated external exposure due to gamma radiation depend primarily on the geological, geographical,altitude 
and mineralogical structures of soil and rocks[2]. Nearly eighty five per cent of the radiation dose received by humanity comes from natural radiation sources[3]. The knowledge of primordial radionuclides is an important prerequisite for the evaluation of the rate of exposure and the absorbed dose by the population. The long-lived naturally occurring radionuclides may get transferred to plants along with the nutrients during mineral uptake,accumulate in various parts and even reach in the edible portions. Abnormal occurrences of uranium and its decay products in rocks and soils and thorium in monazite sands have been identified in several areas of the world[4].

Bangladesh is operating a $3 \mathrm{MW}$ nuclear research reactor, a radioisotope production facility, a high activity gamma irradiation facility as well as other radiological facilities for the benefit of the people of the country.Moreover,Bangladesh is planning to establish nuclear power plants to improve its energy mix. Neighboringcountries have a number of nuclear power plants in operation[5]. Accidents may happen in nuclear installations inside the country as well as in theneighboring countries causing the spread of radioactivity and consequently, influencing the background radiation leveland hence, causing the increase of exposure level to public in this region. Almost every country with nuclear facilities or facilities in neighboring country has its own background radiation mapping database to be used in time of any incident or accident in these nuclear facilities.

The objective of the current study is to estimate the country-wide background radioactivity (mainly- $\gamma$ ) originating from natural and probable artificial radioactive source by dividing the whole country into reasonable systematic square grids [6-7]in order to formulate a countrywide background radioactivity mapping database. The current study is devised to detect the probable radionuclides and estimate their activity concentration on the surface layer of the soil in the area under study.

Theinvestigation has been initiated from around the BAEC TRIGA Research Reactor (BTRR) of Bangladesh situated at Atomic Energy Research Establishment (AERE), Savar, Dhaka located near the 'BhawalGahr'ofGazipurdistrict.The 'BhawalGahr' is mostly an undisturbedforest area spread to the north of the BTRR, has been selected as the starting area for our investigation. The results from this study would produce a baseline radiation map for thisarea which would be used as reference information to assess any change in the background radioactivity level due to the change in the topography of the location,settlement around it as well as any artificial influences on the environment. The study would also provide the current exposure level of the population living in this area due to this background radiation.

\subsection{Geology and Climate of the Sampling Site}

\section{Materials And Method}

'BhawalGahr' areaof Gazipurdistrict was selected as the sampling area. The area is situated in the north, north-east and north-western part of Gazipur bordering Tangail to the west, Mymensingh to the north and Dhaka to the south. The location of 'BhawalGahr'in the satellite map is shown in Fig. 1.The greater 'BhawalGahr' area lies approximately between the latitude $23^{\circ} 54^{\prime} 00^{\prime \prime} \mathrm{N}$ to $24^{\circ} 23^{\prime} 0^{\prime \prime} \mathrm{N}$ and the longitude $90^{\circ} 08^{\prime} 00^{\prime \prime} \mathrm{E}$ to $90^{\circ} 38^{\prime} 00^{\prime \prime}$ E. The area is the second highest terrace of the Madhupur Tract of Pleistocene age. The surface elevation of the site is varying from about 10 to $15 \mathrm{~m}$ above the Mean Sea Level (AMSL), which stands much higher than the general elevation of the surrounding flood plain area. Two characteristic geological units cover the area and the surroundings, viz. Madhupur Clay of the 'Pleistocene Age' and alluvial deposits of 'Recent Age'. The highland alluvium consists of sand, silt and clay. The climatologic characteristic of the region is hot humid with relatively wide temperature range, high rainfall and medium evaporation. On the basis of data collected for the period 2001-2011, it was observed that the mean annual rainfall in the facility area was about $2204 \mathrm{~mm}$ [8]. At that time period the mean annual temperature and relative humidity in the area was $26^{\circ} \mathrm{C}$ and $72 \%$, respectively. The average wind frequency of CALM is dominant around the area. 


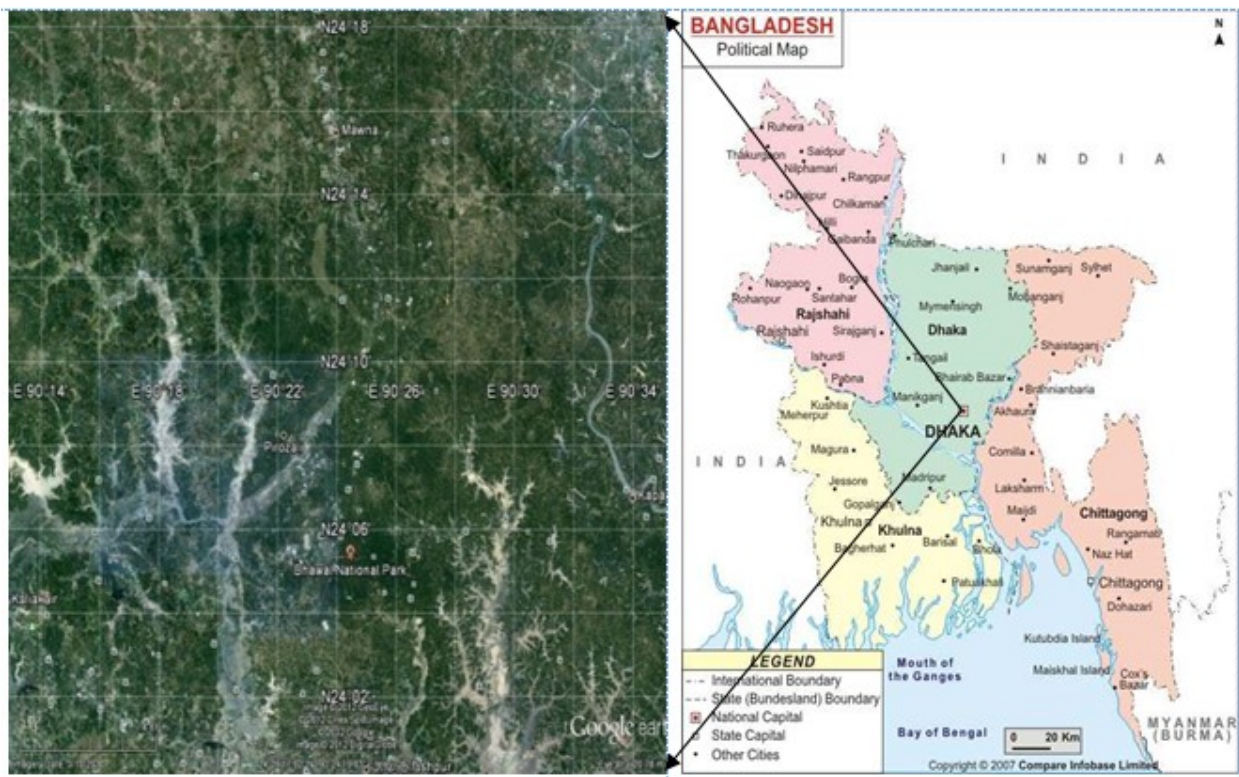

Fig. 1Satellite map of 'BhawalGahr' area comprising of deep forest.

Simultaneously, significant parts of the average wind frequencies are observed at S, SE, N, NE, NW, NNW and W directions. The average annual evaporation rate is about $40 \mathrm{~mm}$ [8]. This area is thinly populated. Industries and human dwellers are rarely found inside the forest; however, densely populated clusters are also seen at some places. The area is mostly covered with 'Shal' (Gazari) trees. However, there are patches of lands inside the forest containing no trees but cultivable lands. Deeplyconcentrated clusters of Gazari trees as well as newly planted trees of different varieties are also seen in some places.

\subsection{Sample Collection and Preservation}

Standard sample collection protocols were followed in sampling in order to maintain high quality of the sampling technique [6-7]. The sampling points were identified using online satellite map before starting the collection of samples. Global Positioning System (GPS) was used to confirm the sampling location in the field level while sampling. The samples were collected from the node-points of the square grids with a distance of $\sim 5$ $\mathrm{km}$. In some cases appropriate sampling node points could not be reached due to various obstacles such as buildings, marshy lands and lack of accessibility. All the relevant and useful data such as environmental condition, demography around the location, soil type, soil color, weather during sampling, time and date of sampling etc. were recorded. A sampling stick with the ID of the location was used during sampling as shown in Fig. 2.

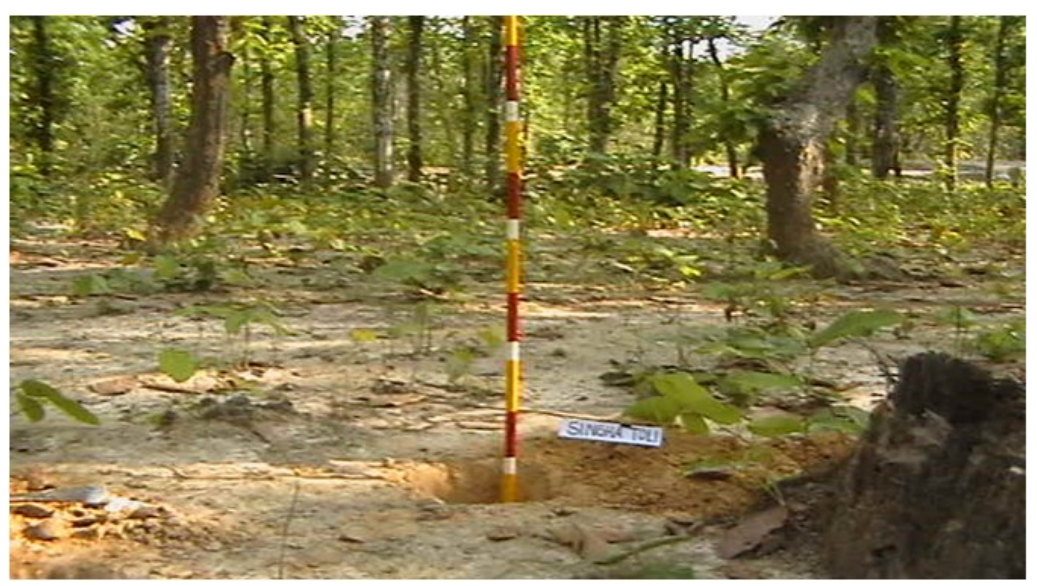

Fig. 2Typical sample collection procedure during the study

Two types of photographs; one close and a panoramic view of the location;were taken during sampling. In order to collect the representative sample a $1 \mathrm{~m} \times 1 \mathrm{~m}$ undisturbed area was selected at each sampling point. Three diagonally equidistance positions were selected within this area.Then on removing the grassroots, pebbles and other unnecessary materials from the selected area soil samples were collected from 0 to $5 \mathrm{~cm}$ depth. The 
three samples were then mixed properly to make the representative sample of that location. A total of 1 (one) $\mathrm{kg}$ of sample was collected from each point. The sample was then kept in a clean plastic packet, marked properly and transported tolaboratory for analysis. Soil samples were collected from 30 differentlocations at $0-5 \mathrm{~cm}$ depth, however, 18 samples are ready for this report and the data for the rest of the samples will be reported later.The samples collected were appropriately coded and standard quality control procedures were followed during sampling, sample preservation and processing [6,9].

\subsection{Sample Processing}

The soil samples were dried in the sun for several daysandthencleaned to remove stone, pebbles, grass roots and straws. The samples were crushed and dried again in a temperature controlled oven at $100^{\circ} \mathrm{C}$ for 24 hours in order to remove the moisture content in it. The dried samples were ground to fine powder and passed through a sieve of $200 \mu \mathrm{m}$ mesh size. The samples were filled and packed in cylindrical plastic containers of 6 $\mathrm{cm}$ diameter and $7 \mathrm{~cm}$ height with a volume of $180 \mathrm{ml}$. The weights of all the samples in the containers were taken by an electronic balance. The net weights of the samples, dates and sample IDs were written down on the top surface of thecontainer and also in a register. Finally, the plastic containers were closed by caps and wrapped with thick vinyl tape about their necks to seal the containers tightly. The samples were then stored for about 4 weeks to assure the secular equilibrium between ${ }^{238} \mathrm{U}$ and ${ }^{232} \mathrm{Th}$ series and their progenies [10]. Fig. 3shows the sample processing steps and the sample containers filled with samples.

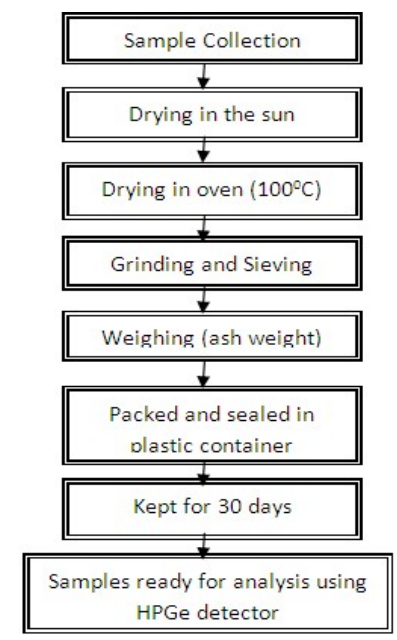

Fig.3(a) Sample processing flow-chart

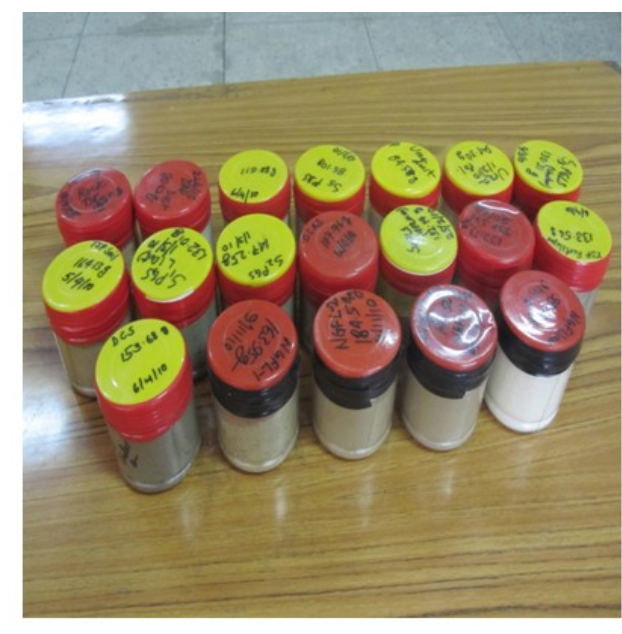

(b) Sample container with samples

\subsection{Sample Analysis}

The characterization (detection of probable radionuclides and estimation of their activity concentration) of the samples were carried out by gamma ray spectrometry technique using a vertical coaxial cylindrical HPGe detector of $20 \%$ relative efficiency. The detector had an active volume of $172 \mathrm{~cm}^{3}$ and was coupled to a $16 \mathrm{k}$ multichannel analyzer (MCA). The analysis was carried out using Genie 2000 software, which matched various gamma energy peaks to a library of possible radionuclides. The detector was enclosed in a cylindrical shielding container made of lead and iron with $11.3 \mathrm{~cm}$ thickness, $51 \mathrm{~cm}$ height and $28 \mathrm{~cm}$ internal diameter and with a fixed bottom and moving cover to reduce the external $\gamma$-ray background during measurement. The measurement system is shown in Fig. 4.All the samples were counted for $10 \mathrm{ks}(10000 \mathrm{sec})$. Prior to the measurement of the samples, the gamma background at the laboratory site was determined with an identical empty plastic container used for the measurement of the samples. The energy range selected for the corresponding radionuclides were $295 \mathrm{keV}$ and $352 \mathrm{keV}$ of ${ }^{214} \mathrm{~Pb}$ and $609 \mathrm{keV}, 1120 \mathrm{keV}$ and $1764 \mathrm{keV}$ of ${ }^{214} \mathrm{Bifor}{ }^{216} \mathrm{Ra}, 583 \mathrm{keV}$ and $2614 \mathrm{keV}$ of ${ }^{214} \mathrm{Tl} 911 \mathrm{keV}$ and $969 \mathrm{keV}$ of ${ }^{228} \mathrm{Ac}$ for ${ }^{228} \mathrm{Th}$ and $1460 \mathrm{keV}$ for ${ }^{40} \mathrm{~K}[10-11]$. 


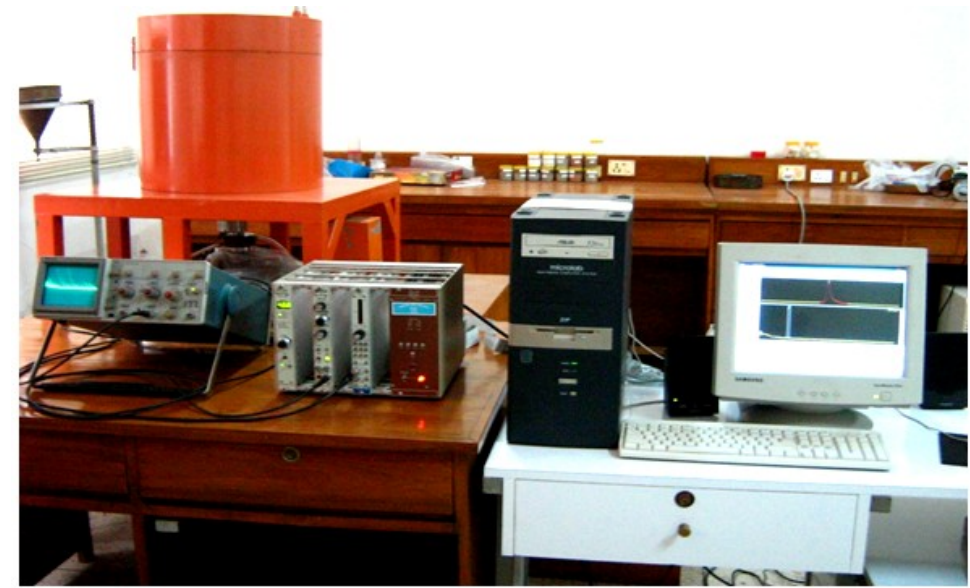

Fig. 4High Purity Germanium (HPGe) detector system for sample analysis

\subsection{Calibration of the HPGe Detector}

In the present study the efficiency calibration of the HPGe detector was performed byastandard source of solid matrix prepared using ${ }^{226} \mathrm{Ra}$ standard solution[12]. The standard source were prepared using an identical container used for the measurement of the samples e.g., the plastic container. The detector efficiency calibration curve as a function of energy for solid matrix is shown in Fig. $\mathbf{5}$.

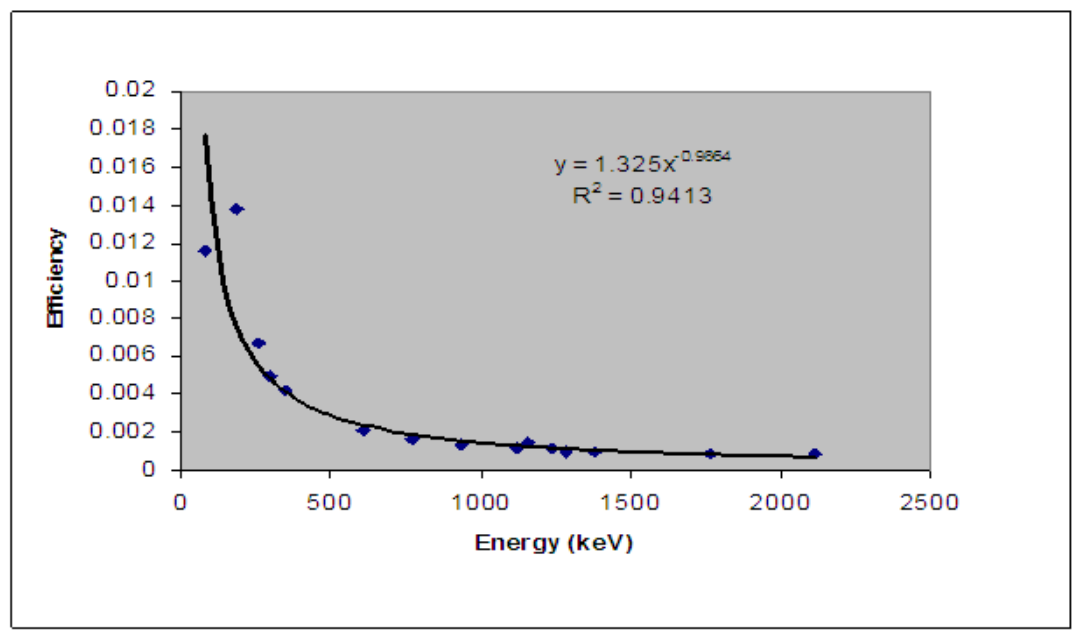

Fig. 5Calibration curve of HPGe detector for solid matrix

\subsection{Calculation of Activity Concentration}

Following the spectrum analysis, count rates for each detected photo-peak and activity per mass unit (specific activity or activity concentration) for each of the detected nuclides were calculated. Calculation of count rates for each detected radionuclides depends on the establishment of secular equilibrium reached between ${ }^{238} \mathrm{U}$ and ${ }^{232} \mathrm{Th}$ and for their decay products. Since the detection system gives only the count rate that is proportional to the amount of radioactivity in the samples, therefore, the net count of a sample was obtained by subtracting a linear background distribution of the pulse height spectra from the corresponding peak energy area.

The radioactivity concentration in the environmental samples was obtained using the following formula[13]:

$$
\mathrm{A}=\frac{\mathrm{cps}}{\mathrm{E} \times \mathrm{I} \times \mathrm{w}}
$$

Where, $\mathrm{A}=$ Activity of the sample in Bq. $\mathrm{kg}^{-1}$

$\mathrm{cps}=$ the net counts per second $=\mathrm{cps}$ for the sample - cps for background value

$\mathrm{E}=$ the counting efficiency of the gamma energy

$\mathrm{I}=$ absolute intensity of the gamma ray and

$\mathrm{w}=$ samples net weight (inkg) 
The errors in the measurement were calculated in terms of standard deviation $\pm \sigma$, where $\sigma$ is expressed as[14]:

$$
\sigma=\left[\frac{\mathrm{N}_{s}}{\mathrm{~T}_{\mathrm{s}}^{2}}+\frac{\mathrm{N}_{\mathrm{b}}}{\mathrm{T}_{\mathrm{b}}^{2}}\right]---------------(2)
$$

Where $\mathrm{N}_{\mathrm{s}}$ is the counts measured in time $\mathrm{T}_{\mathrm{s}}$ and $\mathrm{N}_{\mathrm{b}}$ is the background counts measured in time $\mathrm{T}_{\mathrm{b}}$. The standard deviation $\pm \sigma$ in cps was converted into activity in $\mathrm{Bq} / \mathrm{kg}$ according to equation (1).

\subsection{Calculation of Radiological Hazard Indices}

Radiological impacts of the radionuclides found in the samples were calculated on the basis of calculation of radium equivalent activity, absorbed dose rate calculation, effective dose rate and hazard indexes as given below.

The radionuclides ${ }^{226} \mathrm{Ra},{ }^{232} \mathrm{Th}$ and ${ }^{40} \mathrm{~K}$ are not homogeneously distributed in soil samples. The inhomogeneous distribution from naturally occurring radionuclides is due to disequilibrium between ${ }^{226} \mathrm{Ra}$ and its decay products. For uniformity in exposure estimates, the radionuclide concentrations are defined in terms of 'radium equivalent activity' $\left(\mathrm{Ra}_{\mathrm{eq}}\right)$ in $\mathrm{Bqkg}^{-1}$. This allows comparison of the specific activity of materials containing different amounts of ${ }^{226} \mathrm{Ra},{ }^{232} \mathrm{Th}$ and ${ }^{40} \mathrm{~K}$ according to Beretka and Mathew as follows [15]:

$$
\operatorname{Ra}_{\mathrm{eq}}\left(\mathrm{Bqkg}^{-1}\right)=\mathrm{C}_{\mathrm{Ra}}+1.43 \mathrm{C}_{\mathrm{Th}}+0.077 \mathrm{C}_{\mathrm{K}}------(3)
$$

The external hazard index, $\mathrm{H}_{\mathrm{ex}}$, is defined as [16]:

$$
\mathrm{H}_{\mathrm{ex}}=\left(\frac{\mathrm{C}_{\mathrm{Ra}}}{370}+\frac{\mathrm{C}_{\mathrm{Th}}}{259}+\frac{\mathrm{C}_{\mathrm{K}}}{4810}\right)-----------(6)
$$

The value of this index must be less than unity in order to keep the radiation hazard insignificant.

The absorbed dose rate was calculated from the measured activities of ${ }^{226} \mathrm{Ra},{ }^{232} \mathrm{Th}$ and ${ }^{40} \mathrm{~K}$ in the surface soil samples using the formula given below [17]:

$$
\mathrm{D}\left(\mathrm{nGyh}^{-1}\right)=0.462 \mathrm{C}_{\mathrm{Ra}}+0.604 \mathrm{C}_{\mathrm{Th}}+0.042 \mathrm{C}_{\mathrm{K}}----(4)
$$

Where, $\mathrm{D}$ is absorbed dose rate $\left(\mathrm{nGyh}^{-1}\right.$ ). In natural environmental radioactivity situations, the effective dose is calculated from the absorbed dose by applying the factor as $0.7 \mathrm{~Sv} / \mathrm{Gy}[19]$.

To estimate the outdoor annual effective dose rate, the conversion co-efficient from absorbed dose, 0.7 $\mathrm{SvGy}^{-1}$ and outdoor occupancy factor 0.2 proposed by UNSCEAR, 2000 were used by considering that the people on the average, spent $20 \%$ of their time at outdoors [19]. The effective dose rate in units of $\mathrm{mSvy}^{-1} \mathrm{was}^{-}$ calculated by the following formula:

$$
\left.\mathrm{E}\left(\mathrm{mSvy}^{-1}\right)=\mathrm{D} \times 365.25 \times 0.2 \times 0.7 \times 10^{-6}\right)------(5)
$$

\section{Results And Discussion}

As stated earlier, with the aim to map the country-wide background radiation in Bangladesh, the sample collection was started from around the country's only research reactor (BTRR) at AERE, Savar. Three different batches of samples were collected from at a depth of 0-30 cm (namely, surface soil from 0-5 cm depth, subsurface soils from $5-15 \mathrm{~cm}$ and $15-30 \mathrm{~cm}$ depths) to observe the horizontal and vertical distribution of the radioactivity in the area, however, the results are presented here only for surface soil from 18 locations of the forest and the results on the rest would be reported next. The radionuclides detected and corresponding activity concentrations in different samples have been shown in Table $\mathbf{1 .}$

Table 1: Activity concentrations of the radionuclides in surface soil $(0-5 \mathrm{~cm}$ depth $)$ samples

\begin{tabular}{lcccc}
\hline \multicolumn{1}{c}{ Sampling Location } & GPS ID & ${ }^{226} \mathrm{Ra}(\mathrm{Bq} / \mathrm{kg})$ & ${ }^{232} \mathrm{Th}(\mathrm{Bq} / \mathrm{kg})$ & ${ }^{40} \mathrm{~K}(\mathrm{~Bq} / \mathrm{kg})$ \\
\hline Mouchak & $90^{\circ} 17^{\prime} 39^{\prime \prime} \mathrm{E}, 24^{\circ} 01^{\prime} 23^{\prime \prime} \mathrm{N}$ & $53.07 \pm 5.15$ & $94.08 \pm 8.37$ & $497.39 \pm 94.54$ \\
Shilpigonj-Kalampur & $90^{\circ} 21^{\prime} 25^{\prime \prime} \mathrm{E}, 24^{\circ} 02^{\prime} 10^{\prime \prime} \mathrm{N}$ & $76.01 \pm 10.47$ & $121.32 \pm 10.71$ & $389.32 \pm 106.55$ \\
Kaliakoir FRH & $90^{\circ} 14^{\prime} 35^{\prime \prime} \mathrm{E}, 24^{\circ} 02^{\prime} 43^{\prime \prime} \mathrm{N}$ & $74.71 \pm 9.67$ & $118.58 \pm 9.68$ & $443.81 \pm 102.51$ \\
Kabirpur RS & $90^{\circ} 15^{\prime} 00^{\prime \prime} \mathrm{E}, 24^{\circ} 00^{\prime} 21^{\prime \prime} \mathrm{N}$ & $57.00 \pm 9.65$ & $106.80 \pm 9.84$ & $406.70 \pm 111.31$ \\
Gasbari/Rajbari & $90^{\circ} 19^{\prime} 17^{\prime \prime} \mathrm{E}, 24^{\circ} 8^{\prime} 19^{\prime \prime} \mathrm{N}$ & $81.96 \pm 10.01$ & $125.24 \pm 9.83$ & $362.64 \pm 99.25$
\end{tabular}


Background Gamma Radiation Mapping in Bangladesh: Radioactivity in the Surface.....

\begin{tabular}{lcccc} 
Fulbaria & $90^{\circ} 19^{\prime} 26^{\prime \prime} \mathrm{E}, 24^{\circ} 12^{\prime} 52^{\prime \prime} \mathrm{N}$ & $57.86 \pm 5.80$ & $92.57 \pm 9.03$ & $585.91 \pm 106.13$ \\
Bhonnara/KathaliaChala & $90^{\circ} 17^{\prime} 48^{\prime \prime} \mathrm{E}, 24^{\circ} 02^{\prime} 53^{\prime \prime} \mathrm{N}$ & $49.92 \pm 8.83$ & $76.83 \pm 5.44$ & $410.14 \pm 99.11$ \\
Mawna/Pathar Para & $90^{\circ} 22^{\prime} 57^{\prime \prime} \mathrm{E}, 24^{\circ} 13^{\prime} 42^{\prime \prime} \mathrm{N}$ & $58.64 \pm 5.29$ & $103.05 \pm 8.56$ & $509.68 \pm 93.63$ \\
Bhobanipur & $90^{\circ} 25^{\prime} 11^{\prime \prime} \mathrm{E}, 24^{\circ} 08^{\prime} 38^{\prime \prime} \mathrm{N}$ & $64.97 \pm 5.86$ & $114.17 \pm 9.49$ & $564.68 \pm 103.74$ \\
Sreepur & $90^{\circ} 28^{\prime} 42^{\prime \prime} \mathrm{E}, 24^{\circ} 11^{\prime} 36^{\prime \prime} \mathrm{N}$ & $61.19 \pm 5.66$ & $102.27 \pm 9.62$ & $396.51 \pm 95.81$ \\
Doyai Bari & $90^{\circ} 28^{\prime} 38^{\prime \prime} \mathrm{E}, 24^{\circ} 09^{\prime} 33^{\prime \prime} \mathrm{N}$ & $56.42 \pm 6.24$ & $101.90 \pm 9.28$ & $394.77 \pm 106.06$ \\
Darogachala & $90^{\circ} 24^{\prime} 53^{\prime \prime} \mathrm{E}, 24^{\circ} 12^{\prime} 50^{\prime \prime} \mathrm{N}$ & $56.62 \pm 5.27$ & $91.66 \pm 7.55$ & $550.39 \pm 96.33$ \\
Sonatola/Modya Para & $90^{\circ} 19^{\prime} 29^{\prime \prime} \mathrm{E}, 24^{\circ} 07^{\prime} 00^{\prime \prime} \mathrm{N}$ & $73.79 \pm 6.20$ & $126.45 \pm 8.33$ & $425.05 \pm 102.71$ \\
Aldoba & $90^{\circ} 25^{\prime} 10^{\prime \prime} \mathrm{E}, 24^{\circ} 06^{\prime} 06^{\prime \prime} \mathrm{N}$ & $60.12 \pm 5.50$ & $99.78 \pm 7.93$ & $305.08 \pm 93.63$ \\
Nandail & $90^{\circ} 23^{\prime} 21^{\prime \prime} \mathrm{E}, 24^{\circ} 04^{\prime} 32^{\prime \prime} \mathrm{N}$ & $75.38 \pm 5.72$ & $124.06 \pm 9.04$ & $283.46 \pm 13.35$ \\
Bon Kharia & $90^{\circ} 25^{\prime} 25^{\prime \prime} \mathrm{E}, 24^{\circ} 05^{\prime} 00^{\prime \prime} \mathrm{N}$ & $73.15 \pm 5.57$ & $110.06 \pm 8.66$ & $431.90 \pm 89.91$ \\
BIPSOT & $90^{\circ} 26^{\prime} 34^{\prime \prime} \mathrm{E}, 24^{\circ} 05^{\prime} 15^{\prime \prime} \mathrm{N}$ & $55.08 \pm 5.33$ & $83.53 \pm 9.71$ & $263.71 \pm 92.33$ \\
Hatiabo Gram & $90^{\circ} 24^{\prime} 32^{\prime \prime} \mathrm{E}, 24^{\circ} 02^{\prime} 50^{\prime \prime} \mathrm{N}$ & $83.44 \pm 6.09$ & $124.58 \pm 8.49$ & $414.52 \pm 93.69$ \\
\hline Minimum & & $\mathbf{4 9 . 9 2} \pm \mathbf{8 . 8 3}$ & $\mathbf{7 6 . 8 3} \pm \mathbf{5 . 4 4}$ & $\mathbf{2 6 3 . 7 1} \pm \mathbf{9 2 . 3 3}$ \\
Maximum & & $\mathbf{8 3 . 4 4} \pm \mathbf{6 . 0 9}$ & $\mathbf{1 2 6 . 4 5} \pm \mathbf{8 . 3 3}$ & $\mathbf{5 8 5 . 9 1} \pm \mathbf{1 0 6 . 1 3}$ \\
Average & & $\mathbf{6 6 . 6 8} \pm \mathbf{7 . 4 6}$ & $\mathbf{1 0 1 . 6 4} \pm \mathbf{6 . 8 9}$ & $\mathbf{4 2 4 . 8 1} \pm \mathbf{9 9 . 2 3}$ \\
\hline
\end{tabular}

The radionuclides found in the samples were ${ }^{214} \mathrm{~Pb},{ }^{214} \mathrm{Bi},{ }^{228} \mathrm{Ac},{ }^{208} \mathrm{Tl}$ (due to ${ }^{238} \mathrm{U}$ and ${ }^{232} \mathrm{Th}$ decay) and ${ }^{40} \mathrm{~K}$. There were only natural radionuclides present in the samples and no artificial radionuclide, such as ${ }^{137} \mathrm{Cs}$, ${ }^{90} \mathrm{Sr}$ etc. was found in any of the samples. The values of activity concentrations of ${ }^{226} \mathrm{Ra},{ }^{232} \mathrm{Th}$, and ${ }^{40} \mathrm{~K}$ in the samples collected from 18 different locations ranged from $49.92 \pm 8.83$ to $83.44 \pm 6.09 \mathrm{~Bq} / \mathrm{kg}, 76.83 \pm 5.44$ to $126.45 \pm 8.33 \mathrm{~Bq} / \mathrm{kg}$ and $263.71 \pm 92.33$ to $585.91 \pm 106.13 \mathrm{~Bq} / \mathrm{kg}$, respectively. The maximum values of activity concentrations of ${ }^{226} \mathrm{Ra},{ }^{232} \mathrm{Th}$ and ${ }^{40} \mathrm{~K}$ were found in Hatiabo, Sonatola and Fulbaria whereas the minimum values of activity concentrations for ${ }^{226} \mathrm{Ra},{ }^{232} \mathrm{Th}$ were found inBhonnara and that of ${ }^{40} \mathrm{~K}$ was found in BIPSOT.A comparison of activity concentration values with those of other countries is given in Table 2[20].

Table 2: Comparison of specific activities of radionuclides in soil samples at different locations in 'BhawalGahr' (Bangladesh) with those in other countries as given in [15]

\begin{tabular}{lccc}
\hline \multirow{2}{*}{ Samples } & \multicolumn{3}{c}{ Specific activity of radionuclides $(\mathrm{Bq} / \mathrm{kg})$} \\
\cline { 2 - 4 } & ${ }^{226} \mathrm{Ra}$ & ${ }^{232} \mathrm{Th}$ & ${ }^{40} \mathrm{~K}$ \\
\hline Egypt & 17 & 18 & 320 \\
United States & 40 & 35 & 370 \\
Bangladesh & 34 & - & 350 \\
China & 32 & 41 & 440 \\
Hong Kong SAR & 59 & 95 & 530 \\
India & 29 & 64 & 400 \\
Japan & 33 & 28 & 310 \\
Iran (Islamic Rep. of $)$ & 28 & 22 & 640 \\
Denmark & 17 & 19 & 460 \\
Belgium & 26 & 27 & 380 \\
Luxemburg & 35 & 50 & 620 \\
Switzerland & 40 & 25 & 370 \\
Bulgaria & 45 & 30 & 400 \\
Poland & 26 & 21 & 410 \\
Romania & 32 & 38 & 490 \\
Greece & 25 & 21 & 360 \\
Portugal & 44 & 51 & 840 \\
Spain & 32 & 33 & 470 \\
Thailand & 48 & 40 & 400 \\
Worldwide mean & 33 & 36 & 474 \\
OAP data & 172 & 211 & 511 \\
Present study & $\mathbf{6 5}$ & $\mathbf{1 0 6}$ & $\mathbf{4 2 9}$ \\
\hline
\end{tabular}

The comparison shows that the values of ${ }^{226} \mathrm{Ra} a \mathrm{and}^{232} \mathrm{Th}$ are slightly higher than those found in other countries whereas the value of ${ }^{40} \mathrm{Kis}$ comparable. Radium equivalent activity $\left(\mathrm{Ra}_{\mathrm{eq}}\right)$, external hazard index $\left(\mathrm{H}_{\mathrm{ex}}\right)$, absorbed rate (D) and outdoor annual effective dose (E) to the public were also calculated for these samples [21] and the results are summarized in Table 3. The maximum value of radiation hazard index was calculated to be 0.79 and this value was found in Hatiabo. This value of hazard index is below unity which means that the area is below the critical value or hazardous level.The minimum value was found in Bhonnara which means among 18 
locations studied, this location is less hazardous. The maximum value of annual external effect dose was found in Hatiabo which is $0.16 \mathrm{mSv} / \mathrm{y}$. The minimum value was found to be 0.11 at Bhonnara. The permissible limit of annual effective dose for the public is $1 \mathrm{mSv} / \mathrm{y}$ [22]. Thus, the values of annual effective dose of all the locations under study are below the permissible limit and therefore, there is no possibility of immediate health effect due to this dose to the public in these areas.

Table 3: Radium equivalent activity, radiation hazard index, absorbed dose and annual effective dose to the public calculated from the surface soil $(0-5 \mathrm{~cm}$ depth) samples

\begin{tabular}{|c|c|c|c|c|c|}
\hline Sampling Location & GPS ID & $\begin{array}{c}\text { Radium } \\
\text { Equivalent } \\
\text { Activity, } \mathrm{Ra}_{\mathrm{eq}}\end{array}$ & $\begin{array}{l}\text { External Hazard } \\
\text { Index, } \mathrm{H}_{\mathrm{ex}}\end{array}$ & $\begin{array}{l}\text { Absorbed } \\
\text { Dose } \\
\text { Rate, D } \\
(\mathrm{nGy} / \mathrm{h})\end{array}$ & $\begin{array}{c}\text { Outdoor Annual } \\
\text { Effective Dose, } \\
\text { E (mSv/yr) }\end{array}$ \\
\hline Mouchak & $90^{\circ} 17^{\prime} 39^{\prime \prime} \mathrm{E}, 24^{\circ} 01^{\prime} 23^{\prime \prime} \mathrm{N}$ & 225.74 & 0.61 & 102.24 & 0.13 \\
\hline Shilpigonj & $90^{\circ} 21^{\prime} 25^{\prime \prime} \mathrm{E}, 24^{\circ} 02^{\prime} 10^{\prime \prime} \mathrm{N}$ & 279.27 & 0.75 & 124.74 & 0.15 \\
\hline Kaliakoir FRH & $90^{\circ} 14^{\prime} 35^{\prime \prime} \mathrm{E}, 24^{\circ} 02^{\prime} 43^{\prime \prime} \mathrm{N}$ & 278.25 & 0.75 & 124.78 & 0.15 \\
\hline Kabirpur RS & $90^{\circ} 15^{\prime} 00^{\prime \prime} \mathrm{E}, 24^{\circ} 00^{\prime} 21^{\prime \prime} \mathrm{N}$ & 240.85 & 0.65 & 107.92 & 0.13 \\
\hline Rajbari & $90^{\circ} 19^{\prime} 17^{\prime \prime} \mathrm{E}, 24^{\circ} 8^{\prime} 19^{\prime \prime} \mathrm{N}$ & 288.77 & 0.78 & 128.74 & 0.16 \\
\hline Fulbaria & $90^{\circ} 19^{\prime} 26^{\prime \prime} \mathrm{E}, 24^{\circ} 12^{\prime} 52^{\prime \prime} \mathrm{N}$ & 235.17 & 0.64 & 107.25 & 0.13 \\
\hline Bhonnara & $90^{\circ} 17^{\prime} 48^{\prime \prime} \mathrm{E}, 24^{\circ} 02^{\prime} 53^{\prime \prime} \mathrm{N}$ & 191.23 & 0.52 & 86.69 & 0.11 \\
\hline Mawna & $90^{\circ} 22^{\prime} 57^{\prime \prime} \mathrm{E}, 24^{\circ} 13^{\prime} 42^{\prime \prime} \mathrm{N}$ & 245.05 & 0.66 & 109.43 & 0.13 \\
\hline Bhobanipur & $90^{\circ} 25^{\prime} 11^{\prime \prime} \mathrm{E}, 24^{\circ} 08^{\prime} 38^{\prime \prime} \mathrm{N}$ & 271.51 & 0.73 & 122.69 & 0.15 \\
\hline Sreepur & $90^{\circ} 28^{\prime} 42^{\prime \prime} \mathrm{E}, 24^{\circ} 11^{\prime} 36^{\prime \prime} \mathrm{N}$ & 237.79 & 0.64 & 106.70 & 0.13 \\
\hline Doyai Bari & $90^{\circ} 28^{\prime} 38^{\prime \prime} \mathrm{E}, 24^{\circ} 09^{\prime} 33^{\prime \prime} \mathrm{N}$ & 232.35 & 0.63 & 104.19 & 0.13 \\
\hline DarogaChala & $90^{\circ} 24^{\prime} 53^{\prime \prime} \mathrm{E}, 24^{\circ} 12^{\prime} 50^{\prime \prime} \mathrm{N}$ & 229.90 & 0.62 & 104.64 & 0.13 \\
\hline Nandail & $90^{\circ} 23^{\prime} 21^{\prime \prime} \mathrm{E}, 24^{\circ} 04^{\prime} 32^{\prime \prime} \mathrm{N}$ & 274.34 & 0.74 & 121.61 & 0.15 \\
\hline Bonkharia & $90^{\circ} 25^{\prime} 25^{\prime \prime} \mathrm{E}, 24^{\circ} 05^{\prime} 00^{\prime \prime} \mathrm{N}$ & 261.79 & 0.71 & 118.41 & 0.15 \\
\hline Sonatola & $90^{\circ} 19^{\prime} 29^{\prime \prime} \mathrm{E}, 24^{\circ} 07^{\prime} 00^{\prime \prime} \mathrm{N}$ & 285.92 & 0.78 & 128.32 & 0.16 \\
\hline BIPSOT & $90^{\circ} 26^{\prime} 34^{\prime \prime} \mathrm{E}, 24^{\circ} 05^{\prime} 15^{\prime \prime} \mathrm{N}$ & 195.28 & 0.53 & 86.97 & 0.11 \\
\hline Aldoba & $90^{\circ} 25^{\prime} 10^{\prime \prime} \mathrm{E}, 24^{\circ} 06^{\prime} 06^{\prime \prime} \mathrm{N}$ & 226.14 & 0.61 & 100.86 & 0.12 \\
\hline Hatiabo Gram & $90^{\circ} 24^{\prime} 32^{\prime \prime} \mathrm{E}, 24^{\circ} 02^{\prime} 50^{\prime \prime} \mathrm{N}$ & 292.05 & 0.79 & 131.20 & 0.16 \\
\hline Minimum & & 191.23 & 0.52 & 86.69 & 0.11 \\
\hline Maximum & & 292.05 & 0.79 & 131.20 & 0.16 \\
\hline Average & & 241.64 & 0.66 & 108.95 & 0.14 \\
\hline
\end{tabular}

\section{Conclusion}

The detection of radionuclides and their activity concentrations in soil samples collected from 'BhawalGahr' area of Gazipurdistrict were determined as a part of the country-wide background radiation mapping program. The study also included theassessment of the radiological impact on the public and the environment due to these radionuclides. A total of 18 soil samples were collected from $0-5 \mathrm{~cm}$ depth of soil from across the 'BhawalGahr' area and analyzed for their radioactivity content. The analysis of the samples showed that radionuclides detected in the samples were all natural and no artificial radionuclide was found in the study. The activity concentrations found in the samples were compared with other reported data. This study could be useful as a baseline data for the concentrations of radionuclides in the soil of this area and their radiological impact on the public and environment.

\section{Acknowledgement}

The authorslike to thank the Director of Institute of Nuclear Science and Technology, Atomic Energy Research Establishment, Bangladesh Atomic Energy Commission for allowing using the laboratory facilities of HPRWMU for the work. 


\section{References}

[1]. United States Environmental Protection Agency, Office of Radiation and Indoor Air, EPA 402-F-06-051 | April 2006. Website:www.epa.gov/radtown/soil.html

[2]. UNSCEAR (2000) United Nations Scientific Committee on the effects of atomic radiation, "Effects and risks of ionizing radiations", United Nations, New York.

[3]. Ahmed Al-Haydari, Essam S. A. Al Sharabi and M. H. Al Buhairi, "Determination of Specific Activity of ${ }^{226} \mathrm{Ra},{ }^{232} \mathrm{Th}$ and ${ }^{40} \mathrm{~K}$ for Assessment of Environmental Hazards of Radiation from Building Rock Samples Used in [4] Yemen", Radiation Protection Dosimetry (2011), pp. 1-8.

[4]. G. Shanthi1, C. G. Maniyan, G. Allan Gnana Raj and J. ThampiThankaKumaran, "Radioactivity in food crops from highbackgroundradiation area in southwest India”, CURRENT SCIENCE, Nov. 2009, Vol. 97, No. 9, pp. 1331-1335.

[5]. Operating Experience with Nuclear Power Stations in Member States, IAEA's series of annual reports, Division of Nuclear Power, International Atomic Energy Agency, Vienna International Centre, P O Box 100, 1400 Vienna, Austria.

[6]. Contaminated Land Management Guidelines No.5, Guideline on Site Investigation and Analysis of Soil, Ministry for the Environment, New Zealand. Web-site: http://www.mfe.govt.nz/publications/ser/hazardous/contaminated-land-mgmt-guidelines$\underline{\text { no5/html }}$

[7]. Soil sampling for environmental contaminants, IAEA-TECDOC-1415, October 2004

[8]. Official database of Bangladesh Meteorological Department (BMD) and Bangladesh Water Development Board (BWDB).

[9]. Field Sampling Procedures Manual, New Jersey Department of Environmental Protection, August 2005.

[10]. M. Abusini1, K. Al-ayasreh1 and J. Al-Jundi, "Determination of Uranium, Thorium and PotassiumActivity Concentrations in Soil Cores in Araba Valley, Jordan", Radiation Protection Dosimetry (2008), Vol. 128, No. 2, pp. $213-216$.

[11]. C. E. Roessier, Z.A. Smith, W.E. Bolch and R.J. Prince, "Uranium and radium in Floride phosphate materials", (1970), Health Phys.37:269-277.

[12]. M. S. Tahawy, M.A. Rarouk, F.H. Hammad and N.M. Ibrahiem, "Natural potassium as a standard source for the absolute efficiency calibration of Ge detectors", (1992), Journal of Nuclear Science 29, pp. 361-363.

[13]. M.A. Usif and A.E. Taher, "Radiological assessment of Abu-Tartur phosphate, western desert Egypt"(2008), Radiation Protection Dosimetry 130, pp. 228-235.

[14]. Knoll, G.F., J. Willey and Sons 1998. Radiation Detection and Measurement.Thirdedn.

[15]. Beretka, J. and Mathew, P.J., Natural radioactivity of Australian buildings, materials, industrial wastes and by products, Health Physic, 48, 87-95 (1985).

[16]. Lu, X. And Xiolan, Z. (2006): Measurement of natural radioactivity in sand samples collected from the BoojeWeithe sand park, China, Environ. Geol. 50, 977-988.

[17]. UNSCEAR, 2000. Sources and Effects of Ionizing Radiation.United Nations Scientific Committee on the Effects of Atomic Radiation, United Nations, New York.

[18]. UNSCEAR, 1993. Sources and Effects of Ionizing Radiation.United Nations Scientific Committee on the Effects of Atomic Radiation, United Nations, New York.

[19]. K. Debertin and R.G. Helmer.Gamma and X-ray spectrometry detectors, North Holland, 1988.

[20]. UNSCEAR, 2000 United Nations Scientific Committee on the Effects of Atomic Radiation, Report of UNSCEAR to the General Assembly, United Nations, New York, USA. pp. 111-125.

[21]. P. Kessaratikoon and S. Awaekechi, "Natural radioactivity measurement in soil samples collected from municipal area of Hat Yai district in Songkhla province", (2008), KMITL Sci J. Vol.8, No. 2, pp. 52-58.

[22]. ICRP 1990. Recommendations of the ICRP, Publication 60. 